\title{
Evolutionary Toxicology as a Tool to Assess the Ecotoxicological Risk in Freshwater Ecosystems
}

\author{
Marianna Rusconi ${ }^{1}$, Roberta Bettinetti ${ }^{2}$ (D) , Stefano Polesello $^{1}$ (iD) and Fabrizio Stefani $^{1, * \text { (D) }}$ \\ 1 Water Research Institute, National Research Council (IRSA-CNR), via Mulino 19, 20861 Brugherio, Italy; \\ rusconi@irsa.cnr.it (M.R.); polesello@irsa.cnr.it (S.P.) \\ 2 Department of Theoretical and Applied Sciences, University of Insubria, Via Valleggio 11, 22100 Como, Italy; \\ roberta.bettinetti@uninsubria.it \\ * Correspondence: stefani@irsa.cnr.it; Tel.: +39-039-2169-4232
}

Received: 17 October 2017; Accepted: 11 April 2018; Published: 17 April 2018

\begin{abstract}
Borrowing the approaches of population genetics, evolutionary toxicology was particularly useful in assessing the transgenerational effects of a substance at sublethal concentrations, as well as evaluating genetic variation in populations exposed to pollutants. Starting from assays in controlled conditions, in recent years this approach has also found successful applications multi-stressed natural systems. It is also able to exploit the huge amount of data provided by Next Generation Sequencing (NGS) techniques. Similarly, the focus has shifted from effects on the overall genetic variability, the so-called "genetic erosion", to selective effects induced by contaminants at more specific pathways. In the aquatic context, effects are usually assessed on non-model species, preferably native fish or macroinvertebrates. Here we provide a review of current trends in this specific discipline, with a focus on population genetics and genomics approaches. In addition, we demonstrate the potential usefulness of predictive simulation and Bayesian techniques. A focused collection of field and laboratory studies is discussed to demonstrate the effectiveness of this approach, covering a range of molecular markers, different endpoints of genetic variation, and different classes of chemical contaminants. Moreover, guidelines for a future implementation of evolutionary perspective into Ecological Risk Assessment are provided.
\end{abstract}

Keywords: genetic variability; adaptation; freshwater pollution; risk assessment

\section{Introduction}

In recent years, many genetic approaches have been adopted to investigate the effects of contaminants on gene transcription and evolutionary change. Among these approaches, gene expression (either surveying a set of traditional candidate genes or undertaking a genome-wide analysis) has been widely applied [1], whereas the potential of quantitative genetics and population genetics have only been partially explored [2,3].

In this context, evolutionary toxicology, despite being described more than 20 years ago [4], has only recently been proposed for ecotoxicological assessment [5-8]. In its original definition, the term borrows from the approach of population genetics and aims to identify causal links between toxicant pressures and changes in genetic variability at the population level [9] by applying the approaches and indicators that have proven to be informative in sister disciplines, such as conservation genetics $[10,11]$.

Under this vision, evolutionary toxicology not only fills a gap in the scale of ecotoxicological assessment, but also introduces a novel vision to estimate long-term extinction risk with the awareness that contemporary evolutionary changes are common, widespread, and detectable after only a few generations of contaminant exposure. Evolutionary toxicology, taking into account multigenerational 
effects, can reveal the effects of substances (or mixtures of substances) at sublethal environmental concentrations and over long-term, chronic exposure, both of which are high-priority concerns in making an ecological risk assessment. In fact, effects can accumulate over generations and lead to reductions in fitness and, potentially, to population extinction. In one of the milestone manuscripts of evolutionary toxicology [7], four main research areas were inferred from the existing literature (i.e., the four cornerstones). Contaminants were divided in two main categories: those with a direct effect on nucleic acids (genotoxicants) and those with indirect effects on genetic variability mediated by fitness traits (non-genotoxicants) (Figure 1). Basically, non-genotoxic contaminants may reduce reproductive success, which can increase genetic drift and drive genome-wide changes in genetic diversity, which is referred to as genetic erosion. Additionally, toxicant effects on specific targets or fitness-related traits may determine changes in the allelic or genotypic frequencies as a result of selection at survivorship loci, not involving genome-wide changes but eventually producing side effects, such as increased susceptibility to other contaminants or to other environmental perturbations (fitness trade-offs). Finally, non-genotoxic substances may have cascade effects on behavioral traits, e.g., by limiting or altering the pattern of gene flow among populations. In this case, inbreeding or genetic drift may increase in an isolated population, leading to a loss of gene diversity and creating further fitness-related issues.

Genotoxic substances may have a direct effect on the genome by increasing the mutation rate and altering the balance between purifying the selection and the onset of novel alleles. This effect can be more significant in the case of mildly deleterious alleles, which are less severely purged by selection. The accumulation of deleterious mutations over generations in a population may lead to a mutational load: the negative additive effect of many slightly disadvantageous alleles on fitness traits [9].

Just six years after Bickham's pillar paper [7], Brady et al. [12], introducing a special issue on evolutionary toxicology, provided a paradigmatic analysis of recent trends in this discipline, which clearly set up more ambitious aims and targets thanks to the routine application of Next Generation Sequencing (NGS) techniques in this field. Indeed, the different research areas of evolutionary toxicology have recently coalesced into the characterization of evolutionary patterns, processes, and consequences of adaptation to toxicant exposure (Figure 1). This approach has benefited from the comparative investigation of exposed and control populations of potentially any species on the whole-genome scale as well as from quantitative genetics and epigenetics. In this context, top-down approaches, which aim at identifying the mechanisms underlying chemical resistance or the genomic regions impacted without any a priori knowledge, become prevalent [13]. Moreover, a strong tendency toward the integration of genomic analysis with different experimental approaches, including transcriptomics, proteomics, metabolomics, quantitative genetics, and environmental chemistry, was clearly demonstrated. The intention is to maximally exploit the potential of the NGS data, but more importantly, to better describe the relationships between the exposure of populations to contaminants and their long-term risk of impairment, which is the basis for an effective risk assessment. This task now appears less challenging than just a decade ago because, for example, the direct or indirect fitness costs of adaptation can now be demonstrated by integrating an analysis of phenotypic plasticity (e.g., through transcriptomics scans) with the genomic characterization of exposed and reference populations [14].

Regrettably, evolutionary changes can be evaluated only at a multigenerational scale, limiting their application as a routine effects-based method, as reviewed and discussed in a recent European Guideline [15]. Nevertheless, it is now a common scientific view that evolutionary toxicology will have a role in filling a gap that traditionally exists in ecotoxicological assessments, namely the scarcity of approaches for assessing population effects. By employing population genetic studies, evolutionary toxicology can potentially fill a void that exists between traditional ecotoxicity testing on individual organisms and the assessment of chemical effects on community structure and function.

This paper aims to evaluate the strengths and limitations of evolutionary toxicology as a tool to assess the ecotoxicological risk in freshwater ecosystems by reviewing the existing case studies 
and referring to novel analytical and statistical approaches that have been tested and developed in molecular ecology.

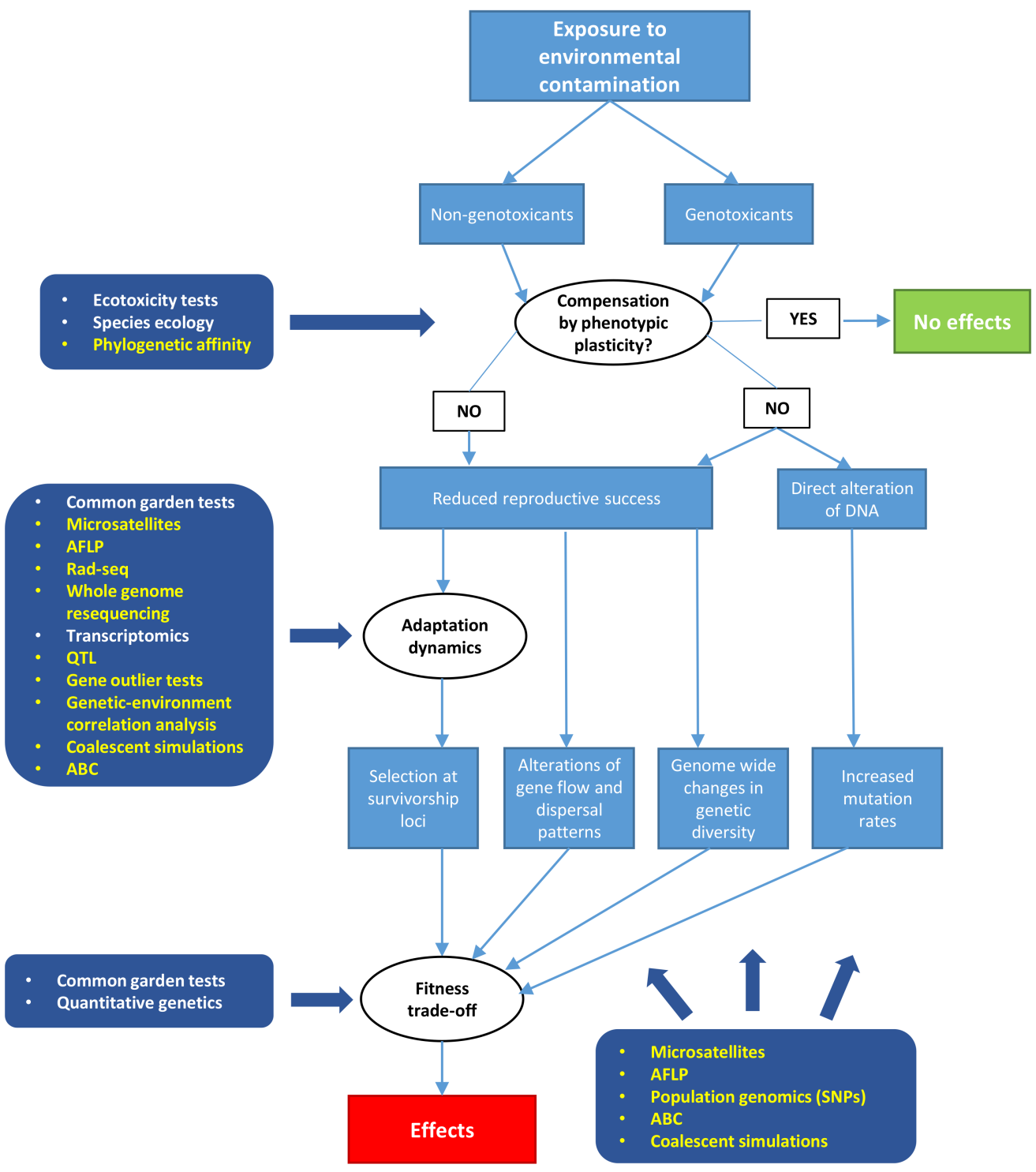

Figure 1. The four main cornerstones of evolutionary toxicology [7], derived from the exposure of populations to non-genotoxicant and genotoxicant contaminants, are presented in light blue. The white blocks represent the main processes leading to the four major responses on an evolutionary scale, which are relevant in the framework of an Ecological Risk Assessment procedure. In the dark blue blocks, the main approaches available to investigate these processes are listed. The techniques specifically discussed in this review are presented in bold yellow. The relevance of contamination for a population may first be evaluated by comparing the sensitivity of the target species with the severity of the expected exposure, and considering the phylogenetic affinity to model species and the potential for physiological compensation. The dynamics of adaptation, genetic erosion, or behavioral alterations may be revealed by a wide range of molecular techniques, including population genetics and genomics, and advanced statistical tools, such as approximate Bayesian computation (ABC). Finally, effects at an evolutionary scale, expressed as fitness trade-offs, can be demonstrated by exposing contaminated populations to singular or multiple stressors. 


\section{The Implementation of Population Genetics and Genomics in Evolutionary Toxicology: Markers, Techniques, and Data Analysis}

The use of genetic techniques to evaluate chemical impacts is relatively recent, and the number of studies in the literature that have applied these techniques to the assessment of freshwater systems is limited, although it is continually growing. Since the first papers conceptualized this discipline $[6,16]$, no more than a few dozen studies specifically addressing the issue of evolutionary toxicology have been published. Moreover, it is only since 2011, with the publication of a special issue of the journal Ecotoxicology on evolutionary toxicology (Reference [5], and papers within the same issue), that this term has been cited and used as keyword. Because a single review with a complete and in-depth discussion of all available approaches to evolutionary responses (e.g., population genetics and genomics, transcriptomics, quantitative genetics, quantitative trait loci, genome-wide association studies, epigenetics) is not possible, we focus primarily on population genetics and genomics, considering the integration with the other approaches where possible. We feel that because evolutionary toxicology is a young discipline, there is still the need to discuss, adapt, and transfer experiences and practices from sister disciplines, such as population genetics and genomics, to this specific field of study. We also consider population genetics and genomics to be one of, if not the most, relevant approaches to address evolutionary responses to contaminants. Specific reviews dealing with the integration of other approaches to ecotoxicology are available [2,17-20].

Signals of genetic alterations (i.e., reduced genetic variability) congruent with toxicant-induced stress were more frequently found in aquatic ecosystems than in terrestrial systems, probably because gene flows are subject to lower interference in aquatic drainages than in open spaces [21]. To date, fishes and macroinvertebrates have been preferably selected as model organisms. Generally, as in traditional toxicological tests, the ecology of the model organisms and their tolerance to toxicants, at least in terms of acute toxicity, should be well characterized and at least a partially sequenced genome should be available, particularly when applying genomic approaches. The molecular markers used for evolutionary toxicology surveys were those typically employed in traditional population genetic studies. Among them, microsatellites have been widely applied. Microsatellite loci are not expected to be under direct selection, although they might be linked to loci that are involved in resistance mechanisms [22-24]. More likely, these markers sample across the genome in a random way, making them useful for measuring the effects of pressures on overall genetic diversity. For organisms with an unknown genome, other versatile techniques such as Amplified Fragment Length Polymorphism (AFLP) [25] have been employed. In fact, these approaches were primarily used in the pre-NGS era, when the focus was on genome-wide genetic erosion, a target that is congruent with their neutral nature and the random location within the genome.

More recently, novel markers (i.e., single nucleotide polymorphisms, SNPs) derived from the application of "omics" techniques, such as restriction site associated DNA sequencing (RAD-seq) or whole-genome sequencing, have been used in evolutionary toxicology and provide a finer resolution for the detection of contaminant-induced selection [26-28]. A specific review on the pros and cons of "omics" techniques in evolutionary toxicology has recently been published [13]. Nevertheless, the potential applications of SNPs in this field are still only partially exploited. One of the main strengths of genomic approaches in comparison with microsatellites is the possibility to better investigate adaptive genetic variation by scanning for contaminant-induced selection. The common endpoints of genetic variation employed in evolutionary toxicology are the same as those used in conservation and population genetics, including heterozygosity, allele richness, Hardy-Weinberg deviations, and fixation indices. Interesting reflections are possible concerning the transferability of these endpoints to the assessment of contaminant-induced effects. The temporal and spatial scales in ecotoxicological assessments are usually more restricted than in classical population genetics studies, where the divergences are commonly evaluated in tens or hundreds of generations or on spatial distances related to relevant natural barriers. Therefore, in many cases, evolutionary toxicological responses, when detectable, can be described only as rapid changes in relation to the expected inertia 
of classic population genetics variations. Even if scientists now agree that contemporary evolutionary changes occurring in a few generations are not occasional but are widespread under natural or human-induced pressures [12,29], the detection of such changes using conventional experimental designs and markers is still challenging, even in the "omics" world.

In this review, we used a simulation approach to evaluate the suitability of standard experimental designs employed in population genetics and genomics with specific reference to rapid evolutionary changes. From this perspective, the implementation of powerful statistical approaches, such as approximate Bayesian computation (ABC) [30], coupled with the increase in polymorphic markers warranted by next-generation sequencing (NGS) techniques, may prove useful either in the planning phase of the assessment or in the inference of processes [31,32]. Indeed, as an example, we verified whether $\mathrm{ABC}$ is able to discriminate a scenario of rapid bottleneck with respect to stationarity by creating experimental designs commonly employed in population genetics and genomic surveys. We simulated genetic variability in a large population $\left(N_{e}=3000\right)$ subject to a strong $\left(N_{e}=100\right)$ or soft $\left(N_{e}=1000\right)$ bottleneck occurring abruptly in 14 generations by using DIYABC 2.1.0 [33] (details in Supplementary Material 1). Then, we verified the confidence in the scenario choice on the basis of the variability provided by 20 or 50 microsatellite loci and 2000 SNP loci. The results, expressed as type I (the probability of incorrectly assigning stationarity in the case of a true bottleneck) and type II (the probability of incorrectly assigning a bottleneck in the case of true stationarity) errors, are reported in Table 1, and indicate unexceptional performances of ABC in both strong and soft bottlenecks with both marker typologies. Only type II errors showed a clear reduction with increasing loci and the magnitude of the bottleneck, and achieved acceptable values. We also simulated the less common case of repeated temporal samples across the 14 generations (50 loci in seven replicate samples) of bottleneck and, under these conditions, both type I and type II error rates were lower, and $\mathrm{ABC}$ appeared to be a potentially suitable tool for optimizing the design of evolutionary toxicology studies (Table 1).

Table 1. Type I and type II error rates of scenario choices performed by approximate Bayesian computation analysis, as obtained by comparing two simulated scenarios of variable bottleneck intensity with respect to a stationary population. Different combinations of marker typology, number of loci and the availability of temporally repeated samples were evaluated.

\begin{tabular}{|c|c|c|c|c|c|}
\hline \multirow{2}{*}{\multicolumn{2}{|c|}{ Markers }} & \multicolumn{4}{|c|}{ Errors } \\
\hline & & \multicolumn{2}{|c|}{ Low Bottleneck } & \multicolumn{2}{|c|}{ High Bottleneck } \\
\hline \multirow{6}{*}{ Microsatellites } & \multirow[b]{2}{*}{20 loci } & Type I & 0.36 & Type I & 0.43 \\
\hline & & Type II & 0.36 & Type II & 0.34 \\
\hline & \multirow[b]{2}{*}{50 loci } & Type I & 0.43 & Type I & 0.35 \\
\hline & & Type II & 0.31 & Type II & 0.09 \\
\hline & \multirow{2}{*}{50 loci (rep. samples) } & Type I & 0.20 & Type I & 0.18 \\
\hline & & Type II & 0.13 & Type II & 0.12 \\
\hline \multirow{2}{*}{ Single nucleotide polymorphisms (SNPs) } & \multirow{2}{*}{2000 loci } & Type I & 0.38 & Type I & 0.46 \\
\hline & & Type II & 0.17 & Type II & 0.14 \\
\hline
\end{tabular}

We also performed a non-Bayesian simulation analysis by using the online optimization tool SPOTG developed by Hoban and colleagues [34] by choosing the temporal module, which allows testing the reliability and resolution of the statistics when past (pre-bottleneck) and present (post-bottleneck) samples are available. We tested the response of statistics, such as the number of polymorphic loci, number of alleles, and heterozygosity in the same bottleneck scenarios, described above by varying the number of microsatellite loci $(10,20$, and 50) and the number of specimens for each of the two samples (20,50, and 100). The final analysis indicated a "power" of detection for each tested experimental design expressed as the percentage of simulated bottleneck datasets that fall within the lowest $5 \%$ of the distribution of a simulated constant population. The simulation results indicated a positive relationship between the magnitude of the bottleneck and the power of detection (Supplementary Materials Tables S1-S3). Regardless of the experimental design employed, 
the soft bottleneck could barely be discriminated, with a maximum power of $69 \%$ when considering the combination of the maximum number of loci and samples. More specifically, the number of markers were inversely correlated with the variance of the statistics; hence, at least 50 microsatellite loci were necessary to achieve low variance and high power ( $<90 \%$ for the strong bottleneck scenario). The number of samples was a less influential variable provided that at least 50 specimens per sample (particularly for contemporary samples) were genotyped. Among the statistics, the number of alleles was generally the most informative variable, but whenever the sample dimension between temporal samples was unequal, normalization by means of a rarefaction analysis was strongly recommended [35].

Here, we have provided only rough guidelines that can be finely tuned for each specific case and used to optimize the experimental plan. For example, the initial $N_{e}$ may have a significant influence on the capacity for discriminating a bottleneck (i.e., genetic erosion) because large, stable populations with larger $N_{e}$ are better able to buffer genetic bottlenecks than small, inbred ones. Nevertheless, two main conclusions can be drawn from this set of simulations. First, the experimental design required to properly analyze a typical, rapid change in genetic variability due to contaminant effects on fitness is demanding, even given the availability of hundreds or thousands of markers available through NGS. In many cases where changes in genetic variability due to contaminant exposure could not be detected, the lack of power or resolution of the chosen experimental design is a likely cause. Second, the availability of temporally repeated samples significantly enhances the performance of the experimental design.

When the research focus is more stringently narrowed towards the detection of adaptation to contaminants, specific molecular analyses such as whole-genome sequencing or RAD-seq become the current gold standard $[13,36]$ and overcome most of the limitations of neutral or nearly neutral markers. In this regard, it is worth mentioning that loci under selection by contaminants usually represent a small proportion (1-6\%) of the scanned genome [37-39], a fact that encourages the use of a wide genomic scan to identify true selected loci, particularly in natural multi-stressed systems. Nevertheless, scanning for the presence of genome regions involved in adaptation is still a challenging task [40-44]. There are still technical limitations on the capacity of genomic approaches to cover all of the regions involved in adaptation [44]. For example, it has been estimated that a RAD-seq coverage with SNPs occurring every $~ 5000 \mathrm{bp}$ would provide a maximum coverage of $\sim 5 \%$ of the genome [41]. Moreover, approaches that imply the enrichment of preferentially coding regions potentially increase the probability of detecting a selected region, and usually discard repetitive regions and enhancers from analysis or do not properly consider duplication events. These elements are typically the basis of gene regulation, a functional property on which adaptation to pollution may often depend $[14,43,45]$.

Other limitations may arise from the incorrect choice of a null population model, on which the detection of selected loci is based in many available approaches and software programs. Demographic properties and events, such as highly structured populations, spatial autocorrelation of allele frequencies, or rapid range expansion, may determine deviations from the models employed by some of the most commonly used software, amplifying their error rates [41]. Moreover, background selection is known to mimic and confound the identification of positive selection [40]. Thus, the possibility of background selection should be taken into account [46], together with the structure and demographic history of a studied population, in the definition of ad hoc null models [40]. Different approaches that attempt to mitigate or overcome these issues have been proposed (see an exhaustive review in Reference [41]). Among those approaches commonly adopted in evolutionary toxicology, genetic differentiation outlier tests aim to distinguish outlier divergent loci from the average divergence of all loci, most of which are assumed to be neutral [28,47], under the assumption that different environmental conditions (i.e., stressed vs. non-stressed) enhance divergence in loci that determine sensitive phenotypes.

Genetic-environment association tests seek atypically high correlations between allele frequencies and the occurrence of contaminants (or other stressors) in exposed and non-exposed populations [36]. 
Specific software packages that allow, as much as possible, the shaping of null models to mirror real case studies are now available, either by adopting genetic differentiation outlier tests (e.g., [48,49]) or appropriate null models (e.g., [50,51]).

Approaches are also available that allow the simulation of datasets, taking into account different demographic events, structures, recombination maps, and different models of selection [52,53]. As in the case of a bottleneck, genotype datasets based on different experimental designs can be simulated and the conditions favoring the detectability of rapid adaptation can be assessed. To date, specific analyses from this perspective have not been published. Moreover, the implementation of selective effects on genetic variability in the framework of tools such as $A B C$ is possible [54,55], even if it is not yet easy to standardize.

\section{Paradigmatic Case Studies}

\subsection{Application in the Field}

Early in the history of evolutionary toxicology, an extensive review of a large set of studies in aquatic environments was published in 2001 [16], emphasizing the promising perspectives for evolutionary ecotoxicology as well as warning about the need for a careful experimental setting to disentangle real patterns among the many co-occurring factors that shape genetic variability. Eighteen years later, with the increasing productivity of NGS techniques and the improved computational power of modern processors, many of the limits highlighted in that review have been scaled down. Nevertheless, many suggestions and precautions remain valid. First, although the implementation of NGS techniques has tremendously increased the information available from genetic datasets, the influence of many other factors that naturally act on genetic variability and structure, such as mutation, recombination, selection, and the genetic architecture of adaptive traits, is still not easily managed, either because of insufficient coverage of the genome or the lack of suitable data analysis techniques that are able to manage such a complexity of variables [56]. Consequently, in some cases a narrower focus on an a priori selected set of candidate genes can be justified to limit the effects of confounding factors.

Another basic approach of field studies is to complement genetic data with a careful and comprehensive assessment of exposure to ensure a representative number of reference and contaminated sites, which allows improved statistical representativeness, and to measure other life trait endpoints, biomarkers, or DNA damage descriptors. Moreover, a precise spatial characterization of stressors (including contaminant distribution and concentrations) is as fundamental as a wide coverage of the genome because the association between exposure to stressors and genome properties is the basis of most of the inferences in evolutionary toxicology [41].

Indeed, differences in genetic variability between impacted and non-impacted populations may not be solely due to contamination. Such changes may be induced by other, often predominant, factors, such as gene flow, random genetic drift, inbreeding, population density, habitat complexity, natural selection, and mutation [57-59]. The condition, not easily fulfilled, to infer a concordant pattern of changes in genetic variability (e.g., selection on specific pathways) in replicated cases of populations exposed to the same contaminants would certainly strengthen the identification of a causative role of contaminants in this regard. A complete list of all published papers on this topic is outside the scope of the present review; therefore, we focus on a few case studies that we consider paradigmatic in this field of study and that have been extensively investigated from multiple perspectives. The choice of these cases allows us to provide a survey of the potential for evolutionary toxicology to implement a risk assessment procedure (Table 2). Many other similar and equally sound studies have been conducted in the field of aquatic evolutionary toxicology. 
Table 2. Field and laboratory case studies described in the review.

\begin{tabular}{|c|c|c|c|c|c|c|}
\hline & Organism & Contaminant & Genetic Assay & Strengths & Opportunities & Reference \\
\hline \multirow{6}{*}{ Field case studies } & Perca flavescens & Metals $(\mathrm{Cu}, \mathrm{Cd})$ & $\begin{array}{l}\text { Microsatellites, de novo } \\
\text { transcriptome scan, } \\
\text { microarrays }\end{array}$ & $\begin{array}{l}\text { Genetic erosion and selection } \\
\text { at unconventional targets were } \\
\text { both detected }\end{array}$ & $\begin{array}{l}\text { Test for adaptation costs } \\
\text { toward other stressors could be } \\
\text { performed }\end{array}$ & {$[10,28,60]$} \\
\hline & Daphnia longispina & Acidity, metals & $\begin{array}{l}\text { AFLP microsatellites, } \\
\text { Comet test }\end{array}$ & $\begin{array}{c}\text { Tight implementation of } \\
\text { quantitative, population } \\
\text { genetics, and } \\
\text { phenotype responses }\end{array}$ & $\begin{array}{l}\text { Only traditional genetics } \\
\text { approaches were employed, no } \\
\text { Next Generation Sequencing } \\
\text { (NGS) data }\end{array}$ & [11] \\
\hline & Solea solea & $\begin{array}{l}\text { Complex mixture of } \\
\text { pesticides and organic } \\
\text { pollutants derived from } \\
\text { agricultural land drainage }\end{array}$ & Microsatellites & $\begin{array}{c}\text { One of the few studies finding } \\
\text { a heterozygosity-fitness } \\
\text { correlation, although at a } \\
\text { single locus }\end{array}$ & $\begin{array}{l}\text { Low number of samples and } \\
\text { markers, inferences at } \\
\text { polygenic level would have } \\
\text { likely benefitted from NGS }\end{array}$ & [61] \\
\hline & Fundulus heteroclitus & Dioxin-like contaminants & $\begin{array}{l}\text { Transcriptomics, genomics, } \\
\text { quantitative genetics }\end{array}$ & $\begin{array}{l}\text { Many different approaches } \\
\text { converge in demonstrating } \\
\text { adaptation to contaminants } \\
\text { and pathways affected }\end{array}$ & $\begin{array}{l}\text { Long-term effects (i.e., genetic } \\
\text { erosion, recovery from } \\
\text { adaptation) are still uncertain } \\
\text { and not predictable }\end{array}$ & [62] \\
\hline & Gammarus pulex & $\begin{array}{l}\text { Effluent of wastewater } \\
\text { treatment plants and } \\
\text { man-made barriers }\end{array}$ & Microsatellites & $\begin{array}{l}\text { Synergic effects of habitat } \\
\text { fragmentation, mutagenic } \\
\text { compounds, and contaminants } \\
\text { exposure were identified }\end{array}$ & $\begin{array}{l}\text { The role of de novo mutations } \\
\text { vs. standing genetic variation } \\
\text { in adaptation to contaminants } \\
\text { (e.g., with genomic approaches) } \\
\text { could be evaluated }\end{array}$ & [63] \\
\hline & $\begin{array}{l}\text { Anguilla anguilla and Anguilla } \\
\text { rostrata }\end{array}$ & PCBs, DDTs, metals & $\begin{array}{l}\text { SNPs generated by restriction } \\
\text { site associated DNA } \\
\text { sequencing (RAD-seq) }\end{array}$ & $\begin{array}{l}\text { Polygenic adaptation was } \\
\text { demonstrated using RAD-seq } \\
\text { polymorphisms analyzed by } \\
\text { the Random Forest technique }\end{array}$ & $\begin{array}{l}\text { The hypothesis of long-term } \\
\text { genetic erosion due to } \\
\text { contaminants could be tested }\end{array}$ & [36] \\
\hline \multirow{3}{*}{$\begin{array}{l}\text { Laboratory case } \\
\text { studies }\end{array}$} & Heterandria formosa & Cadmium & Microsatellites & $\begin{array}{l}\text { A link between adaptation and } \\
\text { overall genetic erosion was } \\
\text { found; limits of closed } \\
\text { multigeneration tests } \\
\text { were undiscovered }\end{array}$ & $\begin{array}{l}\text { Genes underpinning rapid } \\
\text { adaptation cannot be } \\
\text { investigated by using } \\
\text { neutral markers }\end{array}$ & [64] \\
\hline & Chironomus riparius & Tributyltin (TBT) & $\begin{array}{c}\text { Microsatellites } \\
\text { (multigenerational approach) }\end{array}$ & $\begin{array}{l}\text { Effects on genetic variability } \\
\text { were diversified at different } \\
\text { concentrations of TBT; } \\
\text { repeated temporal samples }\end{array}$ & $\begin{array}{l}\text { Low number of neutral } \\
\text { markers, the complex of genes } \\
\text { adapted in relation to TBT } \\
\text { concentration could be } \\
\text { unveiled by integrating NGS }\end{array}$ & {$[65,66]$} \\
\hline & Chironomus riparius & Perfluorinated compounds & $\begin{array}{c}\text { Microsatellites } \\
\text { (multigenerational approach) }\end{array}$ & $\begin{array}{l}\text { Integration of coalescent } \\
\text { simulations approach in } \\
\text { evolutionary toxicology } \\
\text { demonstrating mutation rate } \\
\text { increase; repeated } \\
\text { temporal samples }\end{array}$ & $\begin{array}{l}\text { Low number of markers, } \\
\text { selection could not be tested or } \\
\text { identified, NGS approaches } \\
\text { could be implemented at } \\
\text { this scale }\end{array}$ & [31] \\
\hline
\end{tabular}


Different approaches were used by Bourret et al. [10] and by Belanger et al. [28] to determine the effects of copper and cadmium on yellow perch (Perca flavescens) populations. In the first study, the authors used microsatellites to investigate whether there were significant differences in levels of genetic diversity in yellow perch populations inhabiting lakes with contrasting metal levels and whether individual genetic diversity was associated with the concentration of accumulated metals within individual fish. Microsatellites were applied to individuals collected from lakes in Canadian mining regions representing a gradient of metal (copper and cadmium) contamination. The patterns of contamination within lakes and the effects on major life traits and physiological responses in yellow perch have been previously characterized in detail [67-69], with the finding that regional and seasonal factors, together with contamination, acted to shape responses. The authors not only found genetic differences between individuals from different lakes, but also found that the overall genetic diversity decreased along a gradient of increasing cadmium contamination and that copper contamination may be involved in reducing genetic diversity. Moreover, they also found that although long-term exposure to metals resulted in genetic erosion at the population level, individual genetic diversity was higher in more tolerant individuals, suggesting that less inbred individuals may be favored by selection regardless of the trend in genetic variation within a population. Five years later, Belanger-Deschenes and co-authors used an SNP genome scan to demonstrate the adaptation to $\mathrm{Cd}$ at two candidate loci in the same exposed populations of $P$. flavescens [28], which was reflected in a faster lifecycle leading to early sexual maturation as well as the mitigation of $\mathrm{Cd}$ inhibition for at least one Cd-dependent pathway. Together, these results indicated that a selective response to contamination had been sufficiently influential to reduce genetic diversity and that the long-term capacity of populations to respond to future environmental change was likely compromised.

More recently, a transcriptomics analysis of the same populations of yellow perch revealed different responses when an exposed population was transferred to a clean environment, or vice versa [60]. The analysis highlighted that specific biochemical pathways in fish were activated by contaminants when passing from clean to polluted lakes, including the under-transcription of genes involved in aerobic metabolism, the over-transcription of genes involved in protein folding, and the inhibition of the immune system. In contrast, the absence of transcriptional responses in fish moving from a polluted lake to a clean environment suggests that adaptation rather than phenotypic plasticity is the basis of their increased tolerance. Finally, the long-term potential of adapted populations to cope with other stressors, particularly infectious diseases, can be compromised.

Another noteworthy case study involved killifish (Fundulus heteroclitus) populations that had adapted to heavy pollution in some northern American estuaries [70]. A detailed review of this case has already been published (Reference [62] and the literature cited therein). Briefly, this study represents a fruitful integration of different approaches. Some approaches, such as quantitative genetics, physiology, and development biology, primarily contributed to the identification of adaptation and the main target of selection, which was located in the aryl hydrocarbon receptor (AHR) pathway. Other approaches, such as transcriptomics and genomics, confirmed the inferences and detected a wide range of other pathways implied in adaptation, often population-specific, which may represent responses to local stressors as well as compensatory effects acting differently in each population. Overall, this case study demonstrated that in the presence of high genetic diversity (i.e., large size and high stability of populations) and strong selective pressures, convergent adaptation toward the most influential phenotypic traits is likely.

The case of continuous acid mine drainage (AMD) on a reservoir in Portugal (Chança River Reservoir, Portugal), which carries high concentrations of many trace elements, was studied to test the presence of genetic erosion and selection on Daphnia longispina by comparing local reference and impacted populations (see Ribeiro et al. for a comprehensive review [11]). The integration of quantitative genetics, an assessment of many fitness endpoints and population genetics based on AFLP and microsatellites, allowed fine discrimination of the main genetic impacts and the pattern of responses of the exposed population. Specifically, genetic erosion due to the elimination of the two 
genotypes most sensitive to a 3\% AMD pulse, and due to the avoidance of contaminated areas by the most sensitive genotypes was demonstrated in laboratory testing. A quantitative genetics approach was also employed to demonstrate the genetic basis of tolerance to lethal levels of AMD in genotypes sampled from the contaminated areas, indicating the presence of microevolution. A confirmation of this pattern of genetic erosion (i.e., the disappearance of less resistant lineages in exposed populations) was further demonstrated in the field, allowing the authors to exclude the alternative hypothesis of a spread of newly originated genotypes that conferred resistance. Interestingly, resistance was demonstrated only for the lethal concentration of AMD, but not for sublethal concentrations. Indeed, an analysis of reproductive or feeding life-traits failed to highlight significantly higher fitness in contaminated populations after exposure to sublethal concentrations of AMD or copper. A characterization of neutral genetic diversity in exposed and reference populations failed to prove genetic erosion, even when a significant divergence was detected between them. Gene flow from un-impacted areas of the reservoir and increased mutation or sexual reproduction were among the factors considered to be responsible for this pattern. A later study found mutagenic effects (micronuclei and chromosomal breaks) at $0.1 \%$ AMD [71].

Another study performed in a contaminated estuarine environment was conducted by Guinand et al., who applied a microsatellite approach to young-of-the-year sole (Solea solea) [61]. Sole was selected as the test organism because flatfish exploit estuaries as nursery habitats over long periods during their juvenile phase, and juveniles fail to escape pollution conditions because they are sedentary. Populations sampled at reference sites were compared with three populations sampled in estuaries contaminated by complex mixtures of pesticides and organic pollutants derived from agricultural land drainages. Using 15 genetic markers, the authors demonstrated that in heavily polluted estuaries, most of the variables were significantly different. Genetic variation was shown to be linked to selective and adaptive variation, implying a limited number of loci. Locus-specific heterozygosity-fitness correlations were found for two loci, one of which is implied in heavy metal detoxification, which was indicative of ongoing adaptive selection in sole in response to contamination. These results highlight one of the conceptual pillars of evolutionary toxicology, namely that human activities impact not only the ecological responses of species but also their evolutionary potential to cope with contamination.

Microsatellites were also used also by Inostroza et al. [63] to test the loss of biodiversity in an aquatic ecosystem impacted by mutagens from wastewaters, weirs, and other stressors. In this study, the test organism was Gammarus pulex, sampled along a single river that possessed several chemical sources and man-made barriers. Exposure to chemical pollution alone and in combination with the presence of weirs resulted in a depression of allelic richness in native populations. The input of mutagenic compounds resulted in a strong increase in private alleles across the affected populations, and the presence of weirs along the river disrupted migration along the river and thus the gene flow between up- and downstream individuals. This study demonstrated two of the four cornerstones of evolutionary toxicology [7] in a single case: genetic erosion due to the synergistic effect of habitat fragmentation and contaminant exposure, and an increased mutation rate mirrored in the high frequency of private alleles. The trade-off between these two counteracting drivers is intriguing, and deserves specific in-depth investigations into the genes, particularly by evaluating the relative role of standing genetic variation vs. de novo mutations in the adaptation to contaminants.

Finally, a recent study demonstrated the power of the genomic approach coupled with advanced statistical treatments to infer the effects of contaminants acting on a polygenic base [36]. This is a primary strength of this work because the detection of polygenic adaptation is a challenging task [72]. Genomic RAD-seq assays were employed to test for the presence of polygenic selection in North Atlantic eels, two species that are considered to have a high extinction risk worldwide [73]. The two species, Anguilla anguilla (the European eel) and Anguilla rostrata (the American eel) were used as test replicates and a Random Forest search identified a total of 142 and 141 co-varying loci, respectively, that discriminated "polluted" from "control" populations. Overall, subtle allelic frequency changes were found to be associated with the bioaccumulation of PCB153, pp'-DDE, and selenium. 
Moreover, the authors succeeded in annotating the discriminant markers and concluded that the regulation, absorption, and transport of sterols appeared to play a major role in the differential survival of eels in polluted environments.

\subsection{Laboratory Applications}

Regarding the application of genetic assays in laboratory tests, few works have evaluated long multigenerational exposures. Indeed, in the environment, organisms are often exposed to substances over a time scale that is typically impossible to mimic in the laboratory. To capture population genetic effects, the exposure time must be extended over multiple generations, which is a significant challenge in laboratory ecotoxicological studies. Multigenerational tests can be successfully conducted in only a few species that are easy to breed. However, a well-planned multigenerational test may significantly accelerate processes, such as selection, adaptation, or inbreeding, accomplishing in the laboratory what requires a relatively long time in the field. A multigenerational test, as explained below, can be significantly more realistic from an ecological perspective than normal single generation tests. Indeed, as in the traditional ecotoxicological approach, the controlled conditions of the laboratory test could favor a univocal data interpretation, whereas field studies can be affected by all of the (uncontrolled) variables that are present in a natural ecosystem. Finally, the ability to analyze repeated temporal samples collected during the experiment can significantly improve the resolution of the experimental design, as described in Section 3.1.

Most of the multigenerational experiments published to date are relatively recent and all employ the microsatellite technique. Athrey et al. [64] applied the technique to the least killifish Heterandria formosa to assess the loss of genetic variation in laboratory populations after eight generations of strong selection for an increased resistance to cadmium. The authors compared genetic variation between three selected and three control laboratory populations and between these laboratory populations and the source population by maintaining the same number of breeders (60 specimens) and sex ratio (1:1) between replicates and across generations. A previous analysis found a rapid six-fold increase in resistance and specific fitness costs associated with this adaptation to lethal $\mathrm{Cd}$ concentrations. Heterozygosity was lower in each selected population than in its paired control population, and this difference was statistically significant in two of the three comparisons. Using this genetic approach, the authors demonstrated that adaptation to environmental contaminants can result in an overall loss of genetic variation, and they related this loss to an increased variance in reproduction in exposed populations due to a probable differential survival of families in response to $\mathrm{Cd}$ exposure. This study emphasized that adaptation to lethal levels of a contaminant can induce overall genetic erosion in the absence of external factors counterbalancing the loss of genetic variability. Nevertheless, specific investigations focusing on the genes involved in the adaptation to Cd were not possible based only on seven microsatellite loci. This study also addressed one of the critical points of multigenerational studies: the unavoidable loss of genetic variation in all test populations due to the genetic effective population size imposed by the experimental setting and the absence of external gene flow. In this specific case, the genetic effective population size was estimated to be $\sim 20 \%$ of the census population size in all treatments after eight generations, and the loss of genetic variability due to rearing conditions was significant. Indeed, in all experimental lines, only about two alleles/loci were left and heterozygosity was strongly reduced $(32.11 \%$ and $37.8 \%$ for controls and exposed lines, respectively).

The loss of genetic variation resulting from breeding populations in the laboratory demonstrates that it is important to maintain a large population size and that the potential loss of genetic variation in laboratory populations should be taken into consideration when extrapolating from laboratory to natural populations. Again, the use of simulation approaches could assist in determining the experimental conditions suitable to maintain sufficient genetic variability despite genetic drift, generating a null scenario of random mating, and thus enabling exposed and unexposed populations to be compared. 
Whereas adaptation to lethal levels of contaminants was the focus of the work by Athrey et al., other authors have adopted the multigenerational (12 generations) approach to simulate a long-term chronic and sublethal exposure and to investigate gradual population phenotypic responses to the stressor. In this regard, an interesting case study was proposed by Vogt and Novak $[65,66]$. In their works, the midge (Chironomus riparius) was used as a freshwater model organism to investigate the effects of the highly toxic biocide tributyltin (TBT) at two different sublethal, environmentally relevant concentrations. The study aim was to monitor changes in the population genetic structure as a response to a toxic stress due to adaptation processes or the reduction of neutral genetic variation. In addition to the investigation of genetic variation in the stressed population, fitness-relevant parameters (e.g., mortality and reproduction) were also monitored across all generations. Regarding genetic diversity, it is interesting that the authors found different patterns of response in populations depending on the contaminant concentrations. In the case of milder exposure (4.46 $\mu \mathrm{g} \mathrm{Sn} \mathrm{kg}-1$ sediment, $\mathrm{dw}$ ), no significant differences were found in the level of heterozygosity or allele richness at five microsatellite loci between the exposed and the control populations, but deviations from the Hardy-Weinberg equilibrium accumulated at two loci over the generations in the TBT-exposed populations, suggesting possible selective effects. Moreover, considerable evidence for ongoing adaptation processes was suggested by a significant tolerance to TBT in an acute test and a simultaneous increase in reproductive output in later generations.

This study was preliminary to a second study, which investigated the effects of a nearly doubled concentration of TBT [65]. The experimental plan was the same: a 12-generation test was performed on the same model organism (C. riparius) with the aim of revealing and measure genetic variation in relation to life trait responses. In this second study, a significantly higher decrease in overall genetic variation, in terms of heterozygosity and allele richness, was detected in TBT-exposed populations. No evidence for selection processes was detected, as no significant time trend in any life-history trait was observed, and tolerance towards TBT did not significantly change over time. However, reproductive impairments (increased mortalities and a reduced number of fertile clutches) in most generations were associated with TBT exposure.

Overall, both of the studies appeared to indicate that different intensities of the same stressor modulate the reciprocal balance between selection and genetic drift. Unfortunately, the experimental design did not allow a detailed evaluation of whether the pool of genes under selection varied significantly in the two cases or under the same experimental conditions regardless of the presence of the contaminant. Indeed, it must be remembered that microsatellites are typically neutral markers except when linked to selected traits, which is a highly improbable event given that toxicant-induced selection usually occurs in a very low percentage of loci within the genome.

The results of these studies were fundamental for ratifying the differences between single-generation and multigeneration tests. Indeed, two main lines of evidence emerged against the significance of short-term assays. First, there was high, apparently stochastic, variability in responses linked to life traits, often indicating opposite and contrasting inferences about the toxicity of contaminants from one generation to another [65]. Second, long-term significant effects on genetic variability were present despite the absence of clear phenotypic responses, which appeared to indicate that the traditional tools employed for ecological risk assessment may in many cases underestimate the long-term risk of extinction for resident populations.

In another case study, a different response at the genetic level was found by Stefani and co-workers [31], who aimed to identify the long-term effects of perfluorinated compounds (PFAS), which are very persistent contaminants of emerging concern. According to the experimental framework of Nowak et al. [58], the authors exposed some populations of C. riparius to $10 \mu \mathrm{g} \mathrm{L}{ }^{-1} \mathrm{PFOA}, \mathrm{PFOS}$, or PFBS (two replicates per treatment) for 10 generations, together with two contaminant-free controls.

For the tested substances other than PFOS, low acute toxicity was found for test organisms with standard end-points, indicating toxic concentrations significantly above the levels found in the environment. Genetic analysis demonstrated the maintenance of heterozygosity and allelic diversity in 
PFOS- and PFBS-treated populations with respect to the controls across generations, whereas no effects for PFOA-treated samples were detected despite a general loss of genetic diversity in all treatments due to the experimental design. The results obtained were not indicative of genetic erosion caused by PFASs. On the contrary, a pattern of increased mutation rates emerged as the main transgenerational effect, as demonstrated by the integration of the coalescent simulation approach and the availability of temporally repeated samples and the absence of gene flow. A possible explanation is that an increased mutation rate may have been caused directly by exposure to the contaminant [6] because of the chemical properties of the sulphonate groups carried by PFOS and PFBS, or indirectly by physiological stress [74]. Indeed, exposure to PFOS and PFBS may have induced worse physiological conditions than those observed in the absence of toxicants, and thus generated an increase in mutation rate. A genetic characterization of wild populations of a caddisfly inhabiting a site highly impacted by PFOA demonstrated significant effects (i.e., an altered genetic structure) as well [75].

\section{Potential Role of Evolutionary Toxicology in Ecological Risk Assessments}

The introduction of an evolutionary perspective to the ecological risk assessment (ERA) of chemical contaminants has received limited attention to date, although the integration of evolutionary toxicology with regulatory procedures has been recommended since the dawn of the discipline $[5,7,16]$. Indeed, although a long-term risk for populations linked to the alteration of genetic properties was considered plausible, disentangling this detrimental process from other co-occurring stressors has nevertheless been challenging in many cases [76]. This was in part due to the awareness that the available genetic approaches were scarcely standardizable, often requiring relevant analytical and time resources, and their output was challenging to convert to a risk scale. Here, we illustrate the potential for $\mathrm{ABC}$ simulations to optimize the design of population genetic studies to detect chemical impacts, including both bottlenecks and selection $[30,34,52,53,77]$ (Figure 1). This would allow testing the feasibility of population genetics or genomic surveys in specific contexts to evaluate and quantify the costs necessary to reach significant and acceptable inferences and, at the end of the assay, to provide responses by testing alternative scenarios [31] based on a set of the most informative statistics.

Recently, thanks to the improvement in genetic techniques, more and more studies have succeeded in demonstrating a fundamental role of evolutionary dynamics in determining responses to environmental stressors, including chemical pollution [78,79]. A paradigmatic case study involves the adaptation of Atlantic killifish (Fundulus heteroclitus) to a wide range of toxicants, particularly PCBs, in northern American estuaries [62]. In addition to demonstrating a rapid convergent adaptation that favors the inhibition of the AHR pathway, the primary target of dioxine-like compounds, this study provided the opportunity to draw useful, general guidelines that can be extended to other potential cases and introduced to an ERA framework. First, the intrinsic properties of the exposed populations, such as a high population size, short generation time, and high genetic diversity, increase the probability of a rapid adaptation to toxicants, whereas the opposite conditions could be related to a higher stochastic extinction risk $[46,72,80]$. One might assume (often incorrectly) that species with a higher probability of adaptation would likely be of less concern for protection, whereas rare and endangered taxa would be more prone to extinction when they confront a relevant chemical contamination. Nevertheless, it should be considered that even if adaptation apparently acts as a rescue strategy, it often carries fitness costs, particularly in terms of a decreased resistance to other stressors, which could indirectly impair the long-term persistence of even abundant and prolific species [81-83]. Moreover, abundant species often play a key role in maintaining ecosystem functionality, and their reduced fitness or demographic contraction may significantly impair the provision of ecosystem services [84]. Overall, this guideline can have resounding relevance for conservation prioritization and risk assessment optimization, aiding the choice of suitable and sensitive model taxa for evaluating either short-term risks (i.e., extinction risks via population viability analysis) in the case of endangered and small populations, which likely have limited potential to adapt rapidly, or long-term risks (i.e., fitness costs to adaptation) in the case of abundant and prolific populations. 
Moreover, adaptations to a single or a few prevalent compounds were more likely, more rapid, and less demanding than to a wider mixture of less concentrated pollutants in terms of energetic trade-offs. For example, exposure to pulsed, highly concentrated, specific target toxicants (e.g., pesticides) likely drives the selection of simple phenotypes related to a single or a few physiological targets, whereas chronic exposure to sublethal mixtures of contaminants with multiple modes of action requires the selection of complex, multidimensional phenotypes, which is a less likely process that requires a long time to evolve [62]. In the latter case, further investigations of evolutionary implications may be focused primarily on the first category of contaminants in the context of the process of prioritization of substances for surveillance monitoring.

A corollary of this principle is that the severity of the exposure influences the complexity of genes involved in adaptation. Whenever the intensity of an environmental stressor exceeds the upper tail of the sensitivity distribution of phenotypes within a population, few genes with large effects are typically involved in adaptation. In the case of a milder, prolonged, and gradual intensity of perturbation, polygenic adaptation becomes more likely. Again, it is worth noting that adaptation to a simple complex of genes does not imply that long-term risks may be less relevant than those under polygenic adaptation. Indeed, pleiotropy is a common property of genomes [85], and the indirect effects of selection on numerous phenotypic traits, even those related to a single gene, are frequent, often leading to compensatory adaptations in other genes (assuming that physiological adjustments have failed to restore homeostasis) [86,87].

It is now evident that the long-term adaptation to toxicants is a common phenomenon in nature, and effective mechanisms of resistance and detoxification are often shared between related phylogenetic lineages [88]. This awareness has raised the possibility that the sensitivity of taxa to contaminants could be in some way be predicted by their phylogenetic affinity. For example, some authors [85] provided evidence of a significant correlation between the sensitivity of taxa to chloride, a typical natural stressor that organisms have faced since the transition from marine to freshwater habitats, and their phylogenetic relatedness. Hence, the possibility of estimating toxicity thresholds for untested taxa by extrapolating from the available estimates of related species appears a reasonable approach in ERA to increase ecological realism and to escape from the intrinsic limits of the model species approach [89].

Even the short-term adaptation to toxicants by resident species may have a relevant influence on the ERA. It is well known that the current normative approach has limits in assessing long-term effects, which can persist after the exposure has ceased, particularly under multiple stressor conditions $[8,76]$. Indeed, adaptation to toxicants by wild populations may provide sensitivity to the selective factor or to other stressors, which can be significantly different from that estimated in laboratory assays, which are the basis for the derivation of toxicological thresholds. For example, variation in the response to chloride exposure by adapted and non-adapted conspecific wild populations of two amphibians was large, and exceeded the range of variability estimated among other amphibian species [85]. Consequently, a reasonable improvement in the ERA should not overlook the probability of adaptation by resident populations to pre-existing stressors (Figure 1), and precautionary approaches should be adopted whenever specific assays are not available or conducted.

\section{Conclusions}

Evidence that chemical contaminants may have direct or indirect impacts on the genetic variability of exposed populations is now growing. Moreover, thanks to the integration of NGS approaches, mechanisms and processes of adaptation have been revealed. The negative impacts on the long-term probability of survival of adapted populations are no longer described only as theoretical possibilities, but rather can be tested and hopefully predicted (see examples in References [62,90]).

As demonstrated in the studies reviewed above, the use of a genetic approach can highlight the differences between exposed and reference populations both in laboratory tests and in field research, raising concerns about contaminant effects and the fate of the populations involved. Nevertheless, 
there is also some evidence of a relevant counteracting effect of natural dynamics, such as migration and gene flow, or different synergistic, neutral, or antagonistic interactions of adaptation with other stressors. This is probably one of the most important aspects that should be addressed in the immediate future, with the ultimate aim of improving the predictability of the long-term fate of exposed populations. This consideration should not, however, be assumed to be indicative of a limited relevance of evolutionary changes in the context of ecotoxicological risk assessment. Indeed, the reviewed case studies demonstrated that the investigation of adaptation to contamination, with its intrinsic drawbacks, is greatly improved by the implementation of genomic scan techniques, which are just starting to be massively employed in this discipline.

As suggested by Bourret et al., our review highlights several examples indicating that evolutionary change may occur more rapidly in our lifetime [10] and provides more evidence that human activities are not only affecting the demography and the ecology of wild species, but also their evolutionary trajectory $[76,79]$. This statement alone should be considered sufficient to integrate evolutionary approaches into environmental assessment procedures.

Supplementary Materials: The following are available online at http:/ /www.mdpi.com/2073-4441/10/4/490/ s1.

Acknowledgments: The authors thank the four anonymous reviewers for their fruitful advice on a previous version of the manuscript.

Author Contributions: Marianna Rusconi and Fabrizio Stefani conceived and wrote the review; Roberta Bettinetti and Stefano Polesello gave a critical contribution to the discussion about the possible implementation of evolutionary toxicology in ecotoxicological risk assessment.

Conflicts of Interest: The authors declare no conflict of interest.

\section{References}

1. Simmons, D.B.D.; Benskin, J.P.; Cosgrove, J.R.; Duncker, B.P.; Ekman, D.R.; Martyniuk, C.J.; Sherry, J.P. Omics for aquatic ecotoxicology: Control of extraneous variability to enhance the analysis of environmental effects. Environ. Toxicol. Chem. 2015, 34, 1693-1704. [CrossRef] [PubMed]

2. Klerks, P.L.; Xie, L.; Levinton, J.S. Quantitative genetics approaches to study evolutionary processes in ecotoxicology; a perspective from research on the evolution of resistance. Ecotoxicology 2011, 20, 513-523. [CrossRef] [PubMed]

3. Brown, A.R.; Hosken, D.J.; Balloux, F.; Bickley, L.K.; LePage, G.; Owen, S.F.; Hetheridge, M.J.; Tyler, C.R. Genetic variation, inbreeding and chemical exposure-Combined effects in wildlife and critical considerations for ecotoxicology. Philos. Trans. R. Soc. B Biol. Sci. 2009, 364, 3377-3390. [CrossRef] [PubMed]

4. Anderson, C.; Cunha, L.; Sechi, P.; Kille, P.; Spurgeon, D. Genetic variation in populations of the earthworm, Lumbricus rubellus, across contaminated mine sites. BMC Genet. 2017, 18, 1-13. [CrossRef] [PubMed]

5. Coutellec, M.A.; Barata, C. An introduction to evolutionary processes in ecotoxicology. Ecotoxicology 2011, 20, 493-496. [CrossRef] [PubMed]

6. Bickham, J.W.; Smolen, M.J. Somatic and heritable effects of environmental genotoxins and the emergence of evolutionary toxicology. Environ. Health Perspect. 1994, 102, 25-28. [CrossRef] [PubMed]

7. Bickham, J.W. The four cornerstones of evolutionary toxicology. Ecotoxicology 2011, 20, 497-502. [CrossRef] [PubMed]

8. Stoks, R.; Debecker, S.; Van, K.D.; Janssens, L. Integrating ecology and evolution in aquatic toxicology: Insights from damselflies. Freshw. Sci. 2015, 34, 1032-1039. [CrossRef]

9. Bickham, J. Effects of chemical contaminants on genetic diversity in natural populations: Implications for biomonitoring and ecotoxicology. Mutat. Res. 2000, 463, 33-51. [CrossRef]

10. Bourret, V.; Couture, P.; Campbell, P.G.C.; Bernatchez, L. Evolutionary ecotoxicology of wild yellow perch (Perca flavescens) populations chronically exposed to a polymetallic gradient. Aquat. Toxicol. 2008, 86, 76-90. [CrossRef] [PubMed]

11. Ribeiro, R.; Baird, D.J.; Soares, A.M.V.M.; Lopes, I. Contaminant driven genetic erosion: A case study with Daphnia longispina. Environ. Toxicol. Chem. 2012, 31, 977-982. [CrossRef] [PubMed] 
12. Brady, S.P.; Monosson, E.; Matson, C.W.; Bickham, J.W. Evolutionary toxicology: Toward a unified understanding of life's response to toxic chemicals. Evolut. Appl. 2017, 10, 745-751. [CrossRef] [PubMed]

13. Oziolor, E.M.; Bickham, J.W.; Matson, C.W. Evolutionary toxicology in an omics world. Evolut. Appl. 2017, 10, 752-761. [CrossRef] [PubMed]

14. Shaw, J.R.; Hampton, T.H.; King, B.L.; Whitehead, A.; Galvez, F.; Gross, R.H.; Keith, N.; Notch, E.; Jung, D.; Glaholt, S.P.; et al. Natural selection canalizes expression variation of environmentally induced plasticity-enabling genes. Mol. Biol. Evolut. 2014, 31, 3002-3015. [CrossRef] [PubMed]

15. Wernersson, A.S.; Carere, M.; Maggi, C.; Tusil, P.; Soldan, P.; James, A.; Sanchez, W.; Dulio, V.; Broeg, K.; Reifferscheid, G.; et al. The European technical report on aquatic effect-based monitoring tools under the water framework directive. Environ. Sci. Eur. 2015, 27, 7. [CrossRef]

16. Belfiore, N.M.; Anderson, S.L. Effects of contaminants on genetic patterns in aquatic organisms: A review. Mutat. Res. Rev. Mutat. Res. 2001, 489, 97-122. [CrossRef]

17. Gienapp, P.; Fior, S.; Guillaume, F.; Lasky, J.R.; Sork, V.L.; Csilléry, K. Genomic quantitative genetics to study evolution in the wild. Trends Ecol. Evolut. 2017, 32, 897-908. [CrossRef] [PubMed]

18. Suarez-Ulloa, V.; Gonzalez-Romero, R.; Eirin-Lopez, J.M. Environmental epigenetics: A promising venue for developing next-generation pollution biomonitoring tools in marine invertebrates. Mar. Pollut. Bull. 2015, 98, 5-13. [CrossRef] [PubMed]

19. Peterson, E.K.; Buchwalter, D.B.; Kerby, J.L.; Lefauve, M.K.; Varian-Ramos, C.W.; Swaddle, J.P. Integrative behavioral ecotoxicology: Bringing together fields to establish new insight to behavioral ecology, toxicology, and conservation. Curr. Zool. 2017, 63, 185-194. [CrossRef] [PubMed]

20. Brander, S.M.; Biales, A.D.; Connon, R.E. The role of epigenomics in aquatic toxicology. Environ. Toxicol. Chem. 2017, 36, 2565-2573. [CrossRef] [PubMed]

21. Mussali-galante, P.; Tovar-sánchez, E.; Valverde, M.; Rojas, E. Reviews of Environmental Contamination and Toxicology; Springer: New York, NY, USA, 2014; Volume 227.

22. Selkoe, K.A.; Toonen, R.J. Microsatellites for ecologists: A practical guide to using and evaluating microsatellite markers. Ecol. Lett. 2006, 9, 615-629. [CrossRef] [PubMed]

23. Agnèse, J.F.; Adépo-Gourène, B.; Nyingi, D. Functional microsatellite and possible selective sweep in natural populations of the black-chinned tilapia Sarotherodon melanotheron (Teleostei, Cichlidae). Mar. Genom. 2008, 1, 103-107. [CrossRef] [PubMed]

24. Rengmark, A.H.; Lingaas, F. Genomic structure of the Nile tilapia (Oreochromis niloticus) transferrin gene and a haplotype associated with saltwater tolerance. Aquaculture 2007, 272, 146-155. [CrossRef]

25. Vos, P.; Hogers, R.; Bleeker, M.; Reijans, M.; Lee, T.V.D.; Frijters, A.; Pot, J.; Peleman, J.; Kuiper, M.; Zabeau, M.; et al. AFLP: A new technique for DNA fingerprinting. Nucleic Acids Res. 1995, 23, 4407-4414. [CrossRef] [PubMed]

26. Bouétard, A.; Côte, J.; Besnard, A.-L.; Collinet, M.; Coutellec, M.-A. Environmental versus anthropogenic effects on population adaptive divergence in the freshwater snail Lymnaea stagnalis. PLoS ONE 2014, 9, e106670. [CrossRef] [PubMed]

27. Bouétard, A.; Noirot, C.; Besnard, A.L.; Bouchez, O.; Choisne, D.; Robe, E.; Klopp, C.; Lagadic, L.; Coutellec, M.A. Pyrosequencing-based transcriptomic resources in the pond snail Lymnaea stagnalis, with a focus on genes involved in molecular response to diquat-induced stress. Ecotoxicology 2012, 21, 2222-2234. [CrossRef] [PubMed]

28. Bélanger-Deschênes, S.; Couture, P.; Campbell, P.G.C.; Bernatchez, L. Evolutionary change driven by metal exposure as revealed by coding SNP genome scan in wild yellow perch (Perca flavescens). Ecotoxicology 2013, 22, 938-957. [CrossRef] [PubMed]

29. Hendry, A.P.; Gotanda, K.M.; Svensson, E.I. Human influences on evolution, and the ecological and societal consequences. Philos. Trans. R. Soc. B Biol. Sci. 2017, 372, 20160028. [CrossRef] [PubMed]

30. Csilléry, K.; Blum, M.G.B.; Gaggiotti, O.E.; François, O. Approximate Bayesian Computation (ABC) in practice. Trends Ecol. Evolut. 2010, 25, 410-418. [CrossRef] [PubMed]

31. Stefani, F.; Rusconi, M.; Valsecchi, S.; Marziali, L. Evolutionary ecotoxicology of perfluoralkyl substances (PFASs) inferred from multigenerational exposure: A case study with Chironomus riparius (Diptera, Chironomidae). Aquat. Toxicol. 2014, 156, 41-51. [CrossRef] [PubMed]

32. Momigliano, P.; Jokinen, H.; Fraimout, A.; Florin, A.-B.; Norkko, A.; Merilä, J. Extraordinarily rapid speciation in a marine fish. Proc. Natl. Acad. Sci. USA 2017, 114, 6074-6079. [CrossRef] [PubMed] 
33. Cornuet, J.; Pudlo, P.; Veyssier, J.; Dehne-garcia, A.; Marin, J.; Estoup, A.; Gautier, M.; Cnrs, U.M.R. DIYABC v2. 0: A software to make approximate Bayesian computation inferences about population history using single nucleotide polymorphism, DNA sequence and microsatellite data. Bioinformatics 2018, 30, 1187-1189. [CrossRef] [PubMed]

34. Hoban, S.; Gaggiotti, O.; Bertorelle, G. Sample Planning Optimization Tool for conservation and population Genetics (SPOTG): A software for choosing the appropriate number of markers and samples. Methods Ecol. Evolut. 2013, 4, 299-303. [CrossRef]

35. Hoban, S.; Arntzen, J.A.; Bruford, M.W.; Godoy, J.A.; Rus Hoelzel, A.; Segelbacher, G.; Vilà, C.; Bertorelle, G. Comparative evaluation of potential indicators and temporal sampling protocols for monitoring genetic erosion. Evolut. Appl. 2014, 7, 984-998. [CrossRef] [PubMed]

36. Laporte, M.; Pavey, S.A.; Rougeux, C.; Pierron, F.; Lauzent, M.; Budzinski, H.; Labadie, P.; Geneste, E.; Couture, P.; Baudrimont, M.; et al. RAD sequencing reveals within-generation polygenic selection in response to anthropogenic organic and metal contamination in North Atlantic Eels. Mol. Ecol. 2016, 25, 219-237. [CrossRef] [PubMed]

37. Bach, L.; Dahllöf, I. Local contamination in relation to population genetic diversity and resilience of an arctic marine amphipod. Aquat. Toxicol. 2012, 114-115, 58-66. [CrossRef] [PubMed]

38. Boyer, B. Genome scan in the mosquito Aedes rusticus: Population structure and detection of positive selection after insecticide treatment. Mol. Ecol. 2010, 325-337. [CrossRef]

39. Vega-Retter, C.; Vila, I.; Véliz, D. Signatures of directional and balancing selection in the silverside Basilichthys microlepidotus (Teleostei: Atherinopsidae) inhabiting a polluted river. Evolut. Biol. 2015, 42, 156-168. [CrossRef]

40. Bank, C.; Ewing, G.B.; Ferrer-Admettla, A.; Foll, M.; Jensen, J.D. Thinking too positive? Revisiting current methods of population genetic selection inference. Trends Genet. 2014, 30, 540-546. [CrossRef] [PubMed]

41. Hoban, S.; Kelley, J.L.; Lotterhos, K.E.; Antolin, M.F.; Bradburd, G.; Lowry, D.B.; Poss, M.L.; Reed, L.K.; Storfer, A.; Whitlock, M.C. Finding the genomic basis of local adaptation: Pitfalls, practical solutions, and future directions. Am. Nat. 2016, 188, 379-397. [CrossRef] [PubMed]

42. Hohenlohe, P.A.; Phillips, P.C.; Cresko, W.A. Using population genomics to detect selection in natural populations: Key concepts and methodological considerations. Int. J. Plant Sci. 2011, 171, 1059-1071. [CrossRef] [PubMed]

43. Tiffin, P.; Ross-Ibarra, J. Advances and limits of using population genetics to understand local adaptation. Trends Ecol. Evolut. 2014, 29, 673-680. [CrossRef] [PubMed]

44. Merilä, J.; Hendry, A.P. Climate change, adaptation, and phenotypic plasticity: The problem and the evidence. Evolut. Appl. 2014, 7, 1-14. [CrossRef] [PubMed]

45. Whitehead, A.; Galvez, F.; Zhang, S.; Williams, L.M.; Oleksiak, M.F. Functional genomics of physiological plasticity and local adaptation in killifish. J. Hered. 2011, 102, 499-511. [CrossRef] [PubMed]

46. Comeron, J.M. Background selection as null hypothesis in population genomics: Insights and challenges from Drosophila studies. Philos. Trans. R. Soc. B Biol. Sci. 2017, 372, 20160471. [CrossRef] [PubMed]

47. Proestou, D.A.; Flight, P.; Champlin, D.; Nacci, D. Targeted approach to identify genetic loci associated with evolved dioxin tolerance in Atlantic Killifish (Fundulus heteroclitus). BMC Evolut. Biol. 2014, 14. [CrossRef] [PubMed]

48. Foll, M.; Gaggiotti, O. A genome-scan method to identify selected loci appropriate for both dominant and codominant markers: A Bayesian perspective. Genetics 2008, 180, 977-993. [CrossRef] [PubMed]

49. Vitalis, R.; Gautier, M.; Dawson, K.J.; Beaumont, M.A. Detecting and measuring selection from gene frequency data. Genetics 2014, 196, 799-817. [CrossRef] [PubMed]

50. Günther, T.; Coop, G. Robust identification of local adaptation from allele frequencies. Genetics 2013, 195, 205-220. [CrossRef] [PubMed]

51. Gautier, M. Genome-wide scan for adaptive divergence and association with population-specific covariates. Genetics 2015, 201, 1555-1579. [CrossRef] [PubMed]

52. Messer, P.W. SLiM: Simulating evolution with selection and linkage. Genetics 2013, 194, 1037-1039. [CrossRef] [PubMed]

53. Hernandez, R.D. A flexible forward simulator for populations subject to selection and demography. Bioinformatics 2008, 24, 2786-2787. [CrossRef] [PubMed] 
54. Jensen, J.D.; Thornton, K.R.; Andolfatto, P. An approximate bayesian estimator suggests strong, recurrent selective sweeps in drosophila. PLoS Genet. 2008, 4. [CrossRef] [PubMed]

55. Bazin, E.; Dawson, K.J.; Beaumont, M.A. Likelihood-free inference of population structure and local adaptation in a Bayesian hierarchical model. Genetics 2010, 185, 587-602. [CrossRef] [PubMed]

56. Haasl, R.J.; Payseur, B.A. Fifteen years of genomewide scans for selection: Trends, lessons and unaddressed genetic sources of complication. Mol. Ecol. 2016, 5-23. [CrossRef] [PubMed]

57. Nei, M.; Maruyama, T.; Chakraborty, R. The bottleneck effect and genetic variability in populations. Evolution 1975, 29, 1-10. [CrossRef] [PubMed]

58. Hartl, D.L. A Primer of Population Genetics; Sinauer Associates, Inc.: Sunderland, MA, USA, 2001; p. 221.

59. De Meeûs, T.; Michalakis, Y.; Renaud, F.; Olivieri, I. Polymorphism in heterogeneous environments, evolution of habitat selection and sympatric speciation: Soft and hard selection models. Evolut. Ecol. 1993, 7, 175-198. [CrossRef]

60. Bougas, B.; Normandeau, E.; Grasset, J.; Defo, M.A.; Campbell, P.G.C.; Couture, P.; Bernatchez, L. Transcriptional response of yellow perch to changes in ambient metal concentrations-A reciprocal field transplantation experiment. Aquat. Toxicol. 2016, 173, 132-142. [CrossRef] [PubMed]

61. Guinand, B.; Fustier, M.A.; Labonne, M.; Jourdain, E.; Calvès, I.; Quiniou, L.; Cerqueira, F.; Laroche, J. Genetic structure and heterozygosity-fitness correlation in young-of-the-year sole (Solea solea L.) inhabiting three contaminated West-European estuaries. J. Sea Res. 2013, 80, 35-49. [CrossRef]

62. Whitehead, A.; Clark, B.W.; Reid, N.M.; Hahn, M.E.; Nacci, D. When evolution is the solution to pollution: Key principles, and lessons from rapid repeated adaptation of killifish (Fundulus heteroclitus) populations. Evolut. Appl. 2017, 10, 762-783. [CrossRef] [PubMed]

63. Inostroza, P.A.; Vera-Escalona, I.; Wicht, A.J.; Krauss, M.; Brack, W.; Norf, H. Anthropogenic stressors shape genetic structure: Insights from a model freshwater population along a land use gradient. Environ. Sci. Technol. 2016, 50, 11346-11356. [CrossRef] [PubMed]

64. Athrey, N.R.G.; Leberg, P.L.; Klerks, P.L. Laboratory culturing and selection for increased resistance to cadmium reduce genetic variation in the least killifish, Heterandria formosa. Environ. Toxicol. Chem. 2007, 26, 1916-1921. [CrossRef] [PubMed]

65. Nowak, C.; Vogt, C.; Pfenninger, M.; Schwenk, K.; Oehlmann, J.; Streit, B.; Oetken, M. Rapid genetic erosion in pollutant-exposed experimental chironomid populations. Environ. Pollut. 2009, 157, 881-886. [CrossRef] [PubMed]

66. Vogt, C.; Nowak, C.; Barateiro, J.; Oetken, M.; Schwenk, K. Multi-generation studies with Chironomus riparius-Effects of low tributyltin concentrations on life history parameters and genetic diversity. Chemosphere 2007, 67, 2192-2200. [CrossRef] [PubMed]

67. Couture, P.; Busby, P.; Gauthier, C.; Rajotte, J.W.; Pyle, G.G. Seasonal and regional variations of metal contamination and condition indicators in yellow perch (Perca flavescens) along two polymetallic gradients. I. Factors influencing tissue metal concentrations. Hum. Ecol. Risk Assess. 2008, 14, 97-125. [CrossRef]

68. Couture, P.; Rajotte, J.W.; Pyle, G.G. Seasonal and regional variations in metal contamination and condition indicators in yellow perch (Perca flavescens) along two polymetallic gradients. III. Energetic and physiological indicators. Hum. Ecol. Risk Assess. 2008, 14, 146-165. [CrossRef]

69. Pyle, G.; Busby, P.; Gauthier, C.; Rajotte, J.; Couture, P. Seasonal and regional variations in metal contamination and condition indicators in yellow perch (Perca flavescens) along two polymetallic gradients. II. Growth patterns, longevity, and condition. Hum. Ecol. Risk Assess. 2008, 14, 126-145. [CrossRef]

70. Reid, N.M.; Proestou, D.A.; Clark, B.W.; Warren, W.C.; Colbourne, J.K.; Shaw, J.R.; Karchner, S.I.; Hahn, M.E.; Nacci, D.; Oleksiak, M.F.; et al. The genomic landscape of rapid repeated evolutionary adaptation to toxic pollution in wild fish. Science 2016, 354, 1305-1308. [CrossRef] [PubMed]

71. Sobral, O.; Marin-Morales, M.A.; Ribeiro, R. Could contaminant induced mutations lead to a genetic diversity overestimation? Ecotoxicology 2013, 22, 838-846. [CrossRef] [PubMed]

72. Josephs, E.B.; Stinchcombe, J.R.; Wright, S.I. What can genome-wide association studies tell us about the evolutionary forces maintaining genetic variation for quantitative traits? New Phytol. 2017, 214, 21-33. [CrossRef] [PubMed]

73. The IUCN Red list of Threatened Species. Version 2016-3; Version 20; IUCN (International Union for Conservation of Nature): Gland, Switzerland, 2016.

74. Baer, C.F. Does mutation rate depend on itself. PLoS Biol. 2008, 6, e52. [CrossRef] [PubMed] 
75. Rusconi, M.; Marziali, L.; Stefani, F.; Valsecchi, S.; Bettinetti, R.; Mazzoni, M.; Rosignoli, F.; Polesello, S. Evaluating the impact of a fluoropolymer plant on a river macrobenthic community by a combined chemical, ecological and genetic approach. Sci. Total Environ. 2015, 538, 654-663. [CrossRef] [PubMed]

76. Ashley, M.V.; Willson, M.F.; Pergams, O.R.W.; O’Dowd, D.J.; Gende, S.M.; Brown, J.S. Evolutionarily enlightened management. Biol. Conserv. 2003, 111, 115-123. [CrossRef]

77. Laval, G.; Excoffier, L. SIMCOAL 2.0: A program to simulate genomic diversity over large recombining regions in a subdivided population with a complex history. Bioinformatics 2004, 20, 2485-2487. [CrossRef] [PubMed]

78. Mussali-Galante, P.; Tovar-Sánchez, E.; Valverde, M.; Rojas, E. Genetic Structure and Diversity of Animal Populations Exposed to Metal Pollution BT-Reviews of Environmental Contamination and Toxicology; Whitacre, D.M., Ed.; Springer International Publishing: Cham, Germany, 2014; Volume 227, pp. 79-106, ISBN 978-3-319-01327-5.

79. Smith, T.B.; Bernatchez, L. Evolutionary change in human-altered environments. Mol. Ecol. 2008, 17, 1-8. [CrossRef] [PubMed]

80. Bergland, A.O.; Behrman, E.L.; O’Brien, K.R.; Schmidt, P.S.; Petrov, D.A. Genomic evidence of rapid and stable adaptive oscillations over seasonal time scales in Drosophila. PLoS Genet. 2014, 10. [CrossRef] [PubMed]

81. Acerenza, L. Constraints, trade-offs and the currency of fitness. J. Mol. Evolut. 2016, 82, 117-127. [CrossRef] [PubMed]

82. Dutilleul, M.; Réale, D.; Goussen, B.; Lecomte, C.; Galas, S.; Bonzom, J.M. Adaptation costs to constant and alternating polluted environments. Evolut. Appl. 2017, 10, 839-851. [CrossRef] [PubMed]

83. Shirley, M.D.F.; Sibly, R.M. Genetic basis of a between-environment trade-off involving resistance to Cadmium in Drosophila melanogaster. Evolution 1999, 53, 826-836. [CrossRef] [PubMed]

84. Harrison, P.A.; Berry, P.M.; Simpson, G.; Haslett, J.R.; Blicharska, M.; Bucur, M.; Dunford, R.; Egoh, B.; Garcia-Llorente, M.; Geamănă, N.; et al. Linkages between biodiversity attributes and ecosystem services: A systematic review. Ecosyst. Serv. 2014, 9, 191-203. [CrossRef]

85. Brady, S.P.; Richardson, J.L.; Kunz, B.K. Incorporating evolutionary insights to improve ecotoxicology for freshwater species. Evolut. Appl. 2017, 10, 829-838. [CrossRef] [PubMed]

86. Szamecz, B.; Boross, G.; Kalapis, D.; Kovács, K.; Fekete, G.; Farkas, Z.; Lázár, V.; Hrtyan, M.; Kemmeren, P.; Groot Koerkamp, M.J.A.; Rutkai, E.; Holstege, F.C.P.; et al. The genomic landscape of compensatory evolution. PLoS Biol. 2014, 12. [CrossRef] [PubMed]

87. Wan, J.S.H.; Pang, C.K.; Bonser, S.P. Does the cost of adaptation to extremely stressful environments diminish over time? A literature synthesis on how plants adapt to heavy metals and pesticides. Evolut. Biol. 2017, 44, 411-426. [CrossRef]

88. Palmgren, M.; Engström, K.; Hallström, B.M.; Wahlberg, K.; Søndergaard, D.A.; Sall, T.; Vahter, M.; Broberg, K. AS3MT-mediated tolerance to arsenic evolved by multiple independent horizontal gene transfers from bacteria to eukaryotes. PLoS ONE 2017, 12, e0175422. [CrossRef] [PubMed]

89. Hendriks, A.J. How to deal with 100,000+ substances, sites, and species: Overarching principles in environmental risk assessment. Environ. Sci. Technol. 2013, 47, 3546-3547. [CrossRef] [PubMed]

90. Hua, J.; Wuerthner, V.P.; Jones, D.K.; Mattes, B.; Cothran, R.D.; Relyea, R.A.; Hoverman, J.T. Evolved pesticide tolerance influences susceptibility to parasites in amphibians. Evolut. Appl. 2017, 10, 802-812. [CrossRef] [PubMed]

(C) 2018 by the authors. Licensee MDPI, Basel, Switzerland. This article is an open access article distributed under the terms and conditions of the Creative Commons Attribution (CC BY) license (http:/ / creativecommons.org/licenses/by/4.0/). 